\title{
ANALISIS VALIDITAS MODUL BERBASIS QUANTUM LEARNING TEMA KAYANYA NEGERIKU UNTUK KELAS IV SD
}

\author{
Riri Marfilinda ${ }^{1}$, Widva $^{2}$, Latifah $^{3}$ \\ 1,2,3.STKIP ADZKIA PADANG, Indonesia. \\ Email: riri.m@ stkipadzkia.ac.id, ${ }^{1,2,3}$,
}

\begin{abstract}
The development of a module based on Quantum Learning with the theme Kayanya Negeriku aims to see the product design of a module based on Quantum Learning on the theme of richness of my country in grade IV SD, and to see the results of validation for thematic modules based on Quantum Learning on the theme of richness of my country in grade IV SD. This research was conducted at SD 33 Kalumbuk, Padang City. This research and development process is carried out using the 4-D model), namely defining, designing, developing, and disseminating. Can be trusted as follows: 1) the defining stage is conducting curriculum analysis and analyzing the needs of students, 2) the design stage, carried out by designing the material preparation specifications, preparing tools and materials and module design, the resulting product form in the form of modules / teaching materials using the Quantum Learning model, 3 ) the development stage, is the module validation stage, and the module revision stage. and the dissemination stage was not carried out because considering the conditions of the COVID-19 pandemic so it was not possible to enter the field.

The development was carried out by testing the validity of the module by 3 aspects, namely the material aspect 1 with a value of 3.7 which was very valid category, the design aspect with a value of 3.7 which was very valid category, and the language aspect with a value of 3.6 which was very valid category. Based on the results of the validation of an integrated thematic module based on Quantum Learning, the theme of richness for my country, grade IV SD got an average score of 3.7 in the Very Valid category. This gives an idea that the modules developed are valid and can be used in integrated thematic learning.
\end{abstract}

Keywords: Quantum Learning, Thematic Modules, 4-D Development Model.

\begin{abstract}
ABSTRAK
Pengembangan modul berbasis Quantum Learning dengan tema Kayanya Negeriku bertujuan untuk melihat desain produk modul berbasis Quantum Learning bertema kekayaan negara saya di kelas IV SD, serta melihat hasil validasi modul tematik. berdasarkan Quantum Learning bertema kekayaan negara saya di kelas IV SD. Penelitian ini dilakukan di SD 33 Kalumbuk Kota Padang. Proses penelitian dan pengembangan ini dilakukan dengan menggunakan model 4-D) yaitu pendefinisian, perancangan, pengembangan, dan diseminasi. Yang dapat dipercaya sebagai berikut: 1) tahap pendefinisian yaitu melakukan analisis kurikulum dan menganalisis kebutuhan siswa, 2) tahap perancangan, dilakukan dengan merancang spesifikasi penyiapan materi, menyiapkan alat dan bahan serta desain modul, bentuk produk yang dihasilkan pada bentuk modul / bahan ajar dengan model Quantum Learning, 3) tahap pengembangan, tahap validasi modul, dan tahap revisi modul. dan tahap sosialisasi tidak dilakukan karena mempertimbangkan kondisi pandemi COVID-19 sehingga tidak memungkinkan untuk masuk ke lapangan.

Pengembangan dilakukan dengan menguji validitas modul dengan 3 aspek, yaitu aspek materi 1 dengan nilai 3,7 termasuk kategori sangat valid, aspek desain dengan nilai 3,7 kategori sangat valid, dan aspek kebahasaan. dengan nilai 3,6 yang termasuk kategori sangat valid. Berdasarkan hasil validasi modul tematik terintegrasi berbasis Quantum Learning tema Kekayaan untuk negara saya kelas IV SD mendapat nilai rata-rata 3,7 pada kategori Sangat Valid. Hal ini memberikan gambaran bahwa modul yang dikembangkan valid dan dapat digunakan dalam pembelajaran tematik terintegrasi.
\end{abstract}

Kata Kunci : Pembelajaran Quantum, Modul Tematik, Model Pengembangan 4-D.

\section{PENDAHULUAN}

Pembelajaran di sekolah dasar saat ini memberikan tantangan yang besar bagi seorang pendidik. Penerapan berbagai model belajar di sekolah dasar adalah upaya guru 
dalam melaksanakan pembelajaran di kelas agar lebih efektif, dan efisien. Hal ini diperlukannya seorang guru yang mempunyai penguasaan bahan yang optimal, kemampuan memilih dan menggunakan strategi pembelajaran yang relevan agar dapat mengaktifkan siswa dalam belajar. Dalam keseharian guru dituntut agar dapat berkembang secara percaya diri maupun mandiri dalam meningkatkan kreativitasnya. Guru menciptakan suasana kondusif untuk belajar dan memungkinkan peserta didik dapat berekspresi dengan bebas, menyenangkan dan penuh gairah dalam belajar untuk mempelajari dan memahami esensi berbagai hal yang mereka pelajari (Chan, Kurniawan, Herawati, Nur, \& Mulyani, 2019). Untuk itu dituntut kepiawaian guru dalam melaksanakan pembelajaran yang menantang bagi siswa agar tercipta pembelajaran yang aktif, inovatif, kreatif dan menyenangkan selain itu guru harus mampu memilih dan menggunakan media pembelajaran yang bervariasi. Guru harus menguasai ragam strategi ataupun metoda yang dapat membelajarkan siswa.

Pada sekolah dasar keragaman cara mengajar antara kelas rendah dan kelas tinggi sangat berbeda. Di kelas tinggi menuntut guru untuk mampu menguasai multi metode dan multi media, menciptakan atau mengorganisir lingkungan belajar yang memungkinkan anak belajar penuh tantangan, mampu memecahkan masalah, mengelola kelas dan menggunakan media sumber belajar yang bervariasi. Selama ini yang terjadi dalam aktivitas belajar masih berorientasi pada aktivitas membaca, aktivitas mendengar, dan aktivitas menulis, hal ini mengakibatkan siswa sering merasa cepat bosan dalam belajar, pada proses pembelajaran penulis melihat guru di kelas tinggi khususnya kelas IV masih menggunakan cara-cara lama dalam penyampaian materi pembelajaran yaitu berupa metode konvensional/ceramah. Dan terdapat beberapa siswa kurang bersemangat dalam belajar, siswa masih banyak diam apalagi pada saat guru bertanya pada saat proses pembelajaran berlangsung sehingga kelas menjadi kurang aktif. Selain itu, beberapa sekolah di kota Padang belum mengembangkan bahan ajar berbentuk Modul Tematik Quantum Learning untuk siswa Kelas IV SD.

Quantum Learning merupakan salah satu cara membelajarkan siswa yang digagas oleh Bobbie de Potter. Quantum Learning merupakan suatu kiat, petunjuk, strategi dan seluruh proses belajar yang dapat mempertajam pemahaman dan daya ingat, serta membuat belajar sebagai suatu proses yang menyenangkan dan memberikan makna bagi peserta didik (DePorter, Reardon, \& Singer-Nouri, 2010). Quantum Learning merupakan suatu model pembelajaran yang mana peserta didik dianggap sebagai pusat keberhasilan belajar.

Melalui Quantum Learning siswa akan diajak belajar dalam suasana yang lebih nyaman dan menyenangkan sehingga siswa akan lebih bebas dalam menemukan dan mengemukakan pendapat serta mendapatkan berbagai pengalaman baru dalam belajarnya (Ambarita, Intan, Janah, \& Tarigan, 2020) juga mengungkapkan bahwa Quantum Teaching dapat menjadikan pembelajaran lebih bermakna melalui interaksi yang dinamis guna mengoptimalkan pencapaian prestasi belajar yang tinggi, memberdayakan seluruh potensi yang ada sehingga tercipta suasana belajar nyaman dan menyenangkan. Dalam hal ini, pembelajaran dikemas dalam sebuah modul pembelajaran yang menggunakan langkah-langkah Quantum Learning yang mana di dalamnya akan mengajak siswa belajar dalam suasana yang lebih nyaman dan menyenangkan sehingga siswa akan lebih bebas dalam menemukan berbagai pengalaman baru dengan variasi sumber belajar yang dikemas dalam bentuk media cetak.

Modul merupakan bahan ajar yang dirancang secara sistematik berdasarkan kurikulum tertentu dan dikemas dalam bentuk satuan pembelajaran terkecil dan memungkinkan dipelajari secara mandiri dalam satuan waktu tertentu (Purwanto \& Lasmono, 2007). Penggunaan modul dalam proses pembelajaran telah terbukti mampu 
meningkatkan kualitas pembelajaran. Hal ini dibuktikan dengan hasil penelitian yang diungkapkan oleh beberapa peneliti. Seperti hasil penelitian oleh Izzati (Izzati, Hindarto, \& Pamelasari, 2013) memaparkan bahwa penggunaan modul tematik terbukti mampu meningkatkan karakter siswa secara menyeluruh yang meliputi karakter peduli lingkungan, rasa ingin tahu, percaya diri, komunikatif, mandiri dan gemar membaca, yang mana hal tersebut berdampak pada peningkatan kualitas pembelajaran.

Berdasarkan hal tersebut maka penulis tertarik melakukan penelitian ini dengan tujuan untuk menilai validitas modul berbasis Quantum Learning ditinjau dari beberapa aspek yaitu aspek materi, aspek desain dan aspek bahasa khusus tema kayanya Negeriku di kelas IV Sekolah Dasar.

\section{METODE PENELITIAN}

Metode Penelitian ini merupakan jenis penelitian pengembangan dengan menggunakan desain pengembangan 4-D oleh Thiagarajan (Define, Design, Development dan Disseminate) namun dalam penelitian ini dibatasi hanya sampai tahap development saja yaitu validasi oleh para ahli. .Menurut Sugiyono (Sugiyono, 2010) Penelitian pengembangan ini bertujuan untuk menghasilkan produk tertentu, dan menguji kevalidan produk tersebut. Penelitian ini dilaksanakan di kelas IV SD 33 Kalumbuk Kota Padang yang dilaksanakan pada semester II tahun 2020, dan data diambil pada tanggal 10-11 Maret 2020.

Teknik pengumpulan data menggunakan angket validasi yang terdiri dari validasi materi 2 orang, validasi desain/media 1 orang dan validasi bahasa 1 orang. Pada tahap pendefinisian dilakukan analisis kurikulum dan analisis kebutuhan peserta didik. Pada tahap perancangan, dilakukan dengan merancang spesifikasi penyusunan materi, mempersiapkan alat dan bahan dan rancangan modul, bentuk produk yang dihasilkan berupa modul/bahan ajar dengan menggunakan model Quantum Learning, sedangkan pada tahap pengembangan, adalah tahap validasi modul, dan tahap revisi modul. dan tahap penyebaran tidak dilakukan karena menimbang kondisi yang tidak memungkinkan untuk terjun kelapangan karena kondisi pandemi COVID-19.

Teknik analisis data penelitian terdiri atas dua jenis, yaitu data yang bersifat kualitatif dan kuantitatif. Data kualitatif berupa tanggapan dan saran yang diberikan oleh ahli Desain, ahli konten (materi), ahli bahasa terhadap modul yang dihasilkan. Sedangkan data kuantitatif diambil dari hasil angket berupa angka yang diberikan oleh ahli materi/konten,ahli desain/media dan ahli bahasa pada penilaian validasi modul yang dibuat.

\section{HASIL DAN PEMBAHASAN HASIL PENELITIAN}

Penelitian dan pengembangan modul berbasi Quantum Learning ini dilakukan dengan menggunakan prosedur pengembangan Model 4D yang dikembangkan oleh Thiagarajan yang terdiri dari 4 tahap yaitu tahap pendefinisian (Define), tahap perancangan (Design), tahap pengembangan (Development) dan Penyebaran (Dessiminate) (Thiagarajan, 1974). 1) tahap pendefinisian adalah melakukan analisis kurikulum dan analisis kebutuhan peserta didik, 2) tahap perancangan, dilakukan dengan merancang spesifikasi penyusunan materi, mempersiapkan alat dan bahan dan rancangan modul, bentuk produk yang dihasilkan berupa modul/bahan ajar dengan menggunakan model Quantum Learning, 3) tahap pengembangan, adalah Tahap validasi modul, dan tahap revisi modul. dan tahap penyebaran tidak dilakukan karena menimbang kondisi yang tidak memungkinkan (COVID-19) untuk terjun kelapangan.

Pengembangan dilakukan dengan uji validitas modul oleh 3 aspek, yaitu aspek materi 1 dengan nilai 3,8 dan ahli materi 2 dengan nilai 3,6 sehingga didapatkan rata- 
rata dari ahli materi adalah 3,7 dengan kategori sangat valid (Tabel 1), aspek desain dengan nilai 3.7 yang kategorinya sangat valid (Tabel 2), dan aspek bahasa dengan nilai 3.6 dengan kategori sangat valid (Tabel 3). Berdasarkan hasil validasi modul tematik terpadu berbasis Quantum Learning tema kayanya negeriku kelas IV SD mendapatkan skor rata-rata yaitu 3,7 dengan kategori Sangat Valid. Hal ini memberikan gambaran bahwa modul yang dikembangkan telah valid dan dapat digunakan dalam pembelajaran tematik terpadu.

Tabel 1. Jumlah Skor dari Validator Ahli Materi/konten 1 dan 2

\begin{tabular}{|c|c|c|c|c|c|}
\hline \multirow[t]{2}{*}{ No. } & \multirow[t]{2}{*}{ Aspek Penilaian } & \multicolumn{2}{|c|}{$\begin{array}{l}\text { Validasi Ahli } \\
\text { Materi/Konten }\end{array}$} & \multirow[t]{2}{*}{$\begin{array}{l}\text { Jumlah } \\
\text { Skor }\end{array}$} & \multirow[t]{2}{*}{ Kategori } \\
\hline & & 1 & 2 & & \\
\hline 1. & $\begin{array}{l}\text { Modul tematik terpadu } \\
\text { berbasi Quantum Learning } \\
\text { dapat di pelajari peserta } \\
\text { didik secara mandiri (Self } \\
\text { Instruction) }\end{array}$ & 3 & 4 & 3.5 & Sangat Valid \\
\hline 2. & $\begin{array}{l}\text { Kalimat yang dipakai } \\
\text { sederhana dan langsung } \\
\text { kesasaran }\end{array}$ & 4 & 3 & 3.5 & Sangat Valid \\
\hline 3. & $\begin{array}{l}\text { Isi materi yng ada didalam } \\
\text { modul mudah } \\
\text { diselesaikan/dipecahkan }\end{array}$ & 4 & 4 & 4 & Sangat Valid \\
\hline 4. & $\begin{array}{l}\text { Modul tematik terpadu } \\
\text { berbasi Quantum } \\
\text { Learningmemberikan } \\
\text { penjelasan menarik melalui } \\
\text { teks, gambar serta } \\
\text { pembawan yang } \\
\text { menyenangkan. }\end{array}$ & 4 & 3 & 3.5 & Sangat Valid \\
\hline 5. & $\begin{array}{l}\text { Modul tematik memberikan } \\
\text { kesan yang menarik untuk } \\
\text { dilihat. }\end{array}$ & 3 & 3 & 3 & Valid \\
\hline 6. & $\begin{array}{l}\text { Modul sudah sesuai dengan } \\
\text { langkah-langkah dalam } \\
\text { Quantum Learning yaitu } \\
\text { TANDUR }\end{array}$ & 4 & 4 & 4 & Sangat Valid \\
\hline 7. & $\begin{array}{l}\text { Pertanyaan soal dievaluasi } \\
\text { sesuai dengan materi yang } \\
\text { telah dipaparkan }\end{array}$ & 4 & 4 & 4 & Sangat Valid \\
\hline 8. & $\begin{array}{l}\text { Petunjuk penggunaan modul } \\
\text { mudah dimengerti }\end{array}$ & 4 & 4 & 4 & Sangat Valid \\
\hline 9. & $\begin{array}{l}\text { Modul tematik terp[adu } \\
\text { berbasi Quantum Learning } \\
\text { dapat digunakan sebagai } \\
\text { sumber belajar (Stand } \\
\text { alone) }\end{array}$ & 4 & 3 & 3.5 & Sangat Valid \\
\hline 10. & $\begin{array}{l}\text { Dilengkapi dnlengn tyeka } \\
\text { teki silang yang menarik }\end{array}$ & 4 & 4 & 4 & Sangat Valid \\
\hline & Jumlah & 38 & 36 & 37 & Sangat Valid \\
\hline & Skor & 3.8 & 3.6 & 3.7 & Sangat Valid \\
\hline
\end{tabular}


Tahap validasi ahli materi/konten. Pada tahap ini, validasi dilakukan oleh dosen PGSD STKIP Adzkia Padang,bernama Silfi Melindawati, M.Pd.dan Wakil Kepala sekolah bagian Kurikulum SD Negeri 003/IV Kec. Danau Teluk Kota Jambi.bernama J Jiyanto, S.Pd. Instrumen penelitian untuk ahli materi/konten terdapat 10 aspek. Proses hasil Validasi Ahli Materi/Konten ditempuh dengan1 tahap dengan bantuan 2 orang validator dan diperoleh rata-rata skor 3,7 sehingga, materi dalam modul tematik "Kayanya Negeriku" masuk dalam kriteria penilaian "Sangat Valid" dan modul sudah layak untuk dilakukan uji coba ke siswa tanpa revisi.

Dari hasil saran yang diberikan modul sudah layak digunakan dalam penelitian, Materi dalam modul sudah sesuai dengan karakteristik anak SD.

Tabel 2. Jumlah Skor dari Validator Ahli Desain/media

\begin{tabular}{|c|c|c|c|c|c|c|}
\hline \multirow[t]{2}{*}{ No. } & \multirow[t]{2}{*}{ Aspek Penilaian } & \multicolumn{4}{|c|}{$\begin{array}{l}\text { Validasi Ahli } \\
\text { Desain/media }\end{array}$} & \multirow[t]{2}{*}{ Kategori } \\
\hline & & 1 & 2 & 3 & 4 & \\
\hline 1. & Desain sampul buku menarik & & & & 4 & Sangat Valid \\
\hline 2. & $\begin{array}{l}\text { Penggunaan huruf yang } \\
\text { proposional dan mudah dipahami }\end{array}$ & & & 3 & & Valid \\
\hline 3. & $\begin{array}{l}\text { Gambar yang disajikan jelas, } \\
\text { menarik, dan berwarna }\end{array}$ & & & & 4 & Sangat Valid \\
\hline 4. & Kesesuaian ukuran modul & & & & 4 & Sangat Valid \\
\hline 5. & $\begin{array}{l}\text { Judul modul ditulis jelas singkat } \\
\text { dan komunikatif }\end{array}$ & & & & 4 & Sangat Valid \\
\hline 6. & $\begin{array}{l}\text { Desain modul dan aksesoris } \\
\text { modul menarik }\end{array}$ & & & & 4 & Sangat Valid \\
\hline 7. & $\begin{array}{l}\text { Latihan dan tugas tertulis secra } \\
\text { sistematis }\end{array}$ & & & & 4 & Sangat Valid \\
\hline 8. & $\begin{array}{l}\text { Penulisan petunjukpenggunaan } \\
\text { modul mudah dipahami }\end{array}$ & & & 3 & & Valid \\
\hline 9. & $\begin{array}{l}\text { Pemilihan gambar mendukung } \\
\text { materi pembelajaran }\end{array}$ & & & & 4 & Sangat Valid \\
\hline 10. & $\begin{array}{l}\text { Tujuan pembelajaran tertulis dan } \\
\text { mudah untuk dipahami }\end{array}$ & & & 3 & & Valid \\
\hline & Jumlah & & & 9 & 28 & $\begin{array}{c}37 \\
\text { (Sangat Valid) }\end{array}$ \\
\hline
\end{tabular}

Tahap validasi ahli Desain/media. Pada tahap ini, validasi dilakukan oleh dosen Bapak Alfiyandri,M.Pd. Instrumen penelitian untuk ahli Desain/media terdapat 10 aspek. Proses hasil Validasi Ahli Desain/Media ditempuh dengan1 tahap dan diperoleh rata-rata skor 3,7 sehingga, desain/media dalam modul tematik "Kayanya Negeriku" masuk dalam kriteria penilaian "Sangat Valid" dan modul sudah layak untuk dilakukan uji coba ke siswa tanpa revisi. Dari hasil saran yang diberikan berupa perbaikan penulisan, pemilihan tampilan warna dan font size.

Tabel 3. Jumlah Skor dari Validator Ahli Bahasa

\begin{tabular}{|c|c|c|c|c|c|c|}
\hline \multirow[t]{2}{*}{ No. } & \multirow[t]{2}{*}{ Aspek Penilaian } & \multicolumn{4}{|c|}{$\begin{array}{l}\text { Validasi Ahli } \\
\text { Bahasa }\end{array}$} & \multirow[t]{2}{*}{ Kategori } \\
\hline & & 1 & 2 & 3 & 4 & \\
\hline 1. & $\begin{array}{l}\text { Bahasa yang digunakan tidak } \\
\text { memiliki makna ganda }\end{array}$ & & & & 4 & Sangat Valid \\
\hline 2. & $\begin{array}{l}\text { Kalimat yang digunakan } \\
\text { menggunakan bahasa baku } \\
\text { sesuai PEUBI(Pedoman Umum }\end{array}$ & & & & 4 & Sangat Valid \\
\hline
\end{tabular}




\begin{tabular}{|c|c|c|c|c|}
\hline \multicolumn{5}{|c|}{ Ejaan Bahasa Indonesia) } \\
\hline 3. & $\begin{array}{l}\text { Kalimatyang digunakan } \\
\text { sederhana jelas dan mudah } \\
\text { dipahami }\end{array}$ & & 4 & Sangat Valid \\
\hline 4. & Ide tersusun dengan tertib & & 4 & Sangat Valid \\
\hline 5. & $\begin{array}{l}\text { Kalimat yang digunakan } \\
\text { melibatkan kemampuan berpikir } \\
\text { logis }\end{array}$ & 3 & & Valid \\
\hline 6. & $\begin{array}{l}\text { Kalimat yang digunakan sesuai } \\
\text { dengan kaidah bahasa Indonesia }\end{array}$ & 3 & & Valid \\
\hline 7. & $\begin{array}{l}\text { Kesesuaian kalimat pada pada } \\
\text { materi sesuai dengan tingkat } \\
\text { kemampuan peserta didik }\end{array}$ & 3 & & Valid \\
\hline 8. & $\begin{array}{l}\text { Istilah kosakata yang digunakan } \\
\text { tepat }\end{array}$ & & 4 & Sangat Valid \\
\hline 9. & $\begin{array}{l}\text { Kesesuaian kalimat pad } \\
\text { pertanyaan sesuai dengan tingkat } \\
\text { kemampuan peserta didik }\end{array}$ & 3 & & Valid \\
\hline 10. & $\begin{array}{l}\text { Kalimat yang dipakai sederhana } \\
\text { dan mudah dipahami. }\end{array}$ & & 4 & Sangat Valid \\
\hline & Jumlah & 12 & 24 & $\begin{array}{c}36 \\
\text { (Sangat Valid) }\end{array}$ \\
\hline
\end{tabular}

Tahap validasi yang dilakukan oleh ahli Bahasa. Pada tahap ini, validasi dilakukan oleh dosen Bapak Dr. Jendriadi, M.Pd. Instrumen penelitian untuk ahli bahasa terdapat 10 aspek. Dari hasil saran yang diberikan "modul tematik berbasis quantum learning telah berusaha dibuat dengan aturan di pedoman bahasa, hanya sedikit penulisan yang perlu diperbaiki lagi agar lebih rapi lagi" dan modul dinyatakan layak uji coba lapangan dengan revisi sesuai saran.

Hasil revisi sudah sesuai dengan karakteristik modul yang disampaikan oleh Sukiman (2012: 133) bahwa dalam mengembangkan modul perlu memenuhi kaidah user friendly atau mudah digunakan oleh siswa. Baik segi instruksi atau informasi yang diberikan mempermudah siswa, penggunaan bahasa yang sederhana dan mudah dimengerti.

Tabel 4. Hasil Akhir dari Nilai Rata-Rata Validator

\begin{tabular}{|c|c|c|c|c|}
\hline Para Ahli & Nilai & Rata-rata & $\begin{array}{l}\text { Kategori } \\
\text { Validitas }\end{array}$ & Keterangan \\
\hline Ahli Materi/konten. 1 & 3,6 & $\frac{7,4}{2}=3,7$ & Sangat Valid & $\begin{array}{lr}\text { Layak } & \text { untuk } \\
\text { uji } & \text { coba } \\
\text { lapangan } & \text { tanpa } \\
\text { revisi } & \\
\end{array}$ \\
\hline Ahli Materi/konten. 2 & 3,8 & & Sangat Valid & $\begin{array}{lr}\text { Layak } & \text { untuk } \\
\text { uji } & \text { coba } \\
\text { lapangan } & \text { tanpa } \\
\text { revisi. } & \\
\end{array}$ \\
\hline Ahli Desain/Media & 3,7 & 3,7 & Sangat Valid & $\begin{array}{lr}\text { Layak } & \text { untuk } \\
\text { uji } & \text { coba } \\
\text { lapangan } & \text { tanpa } \\
\text { revisi. } & \\
\end{array}$ \\
\hline
\end{tabular}




\begin{tabular}{|c|c|c|c|c|}
\hline Ahli Bahasa & 3,6 & 3,6 & Sangat Valid & $\begin{array}{lr}\text { Layak } & \text { untuk } \\
\text { uji } & \text { coba } \\
\text { lapangan } & \text { tanpa } \\
\text { revisi. } & \\
\end{array}$ \\
\hline Rata-rata & & & $\begin{array}{l}\text { 3,7 } \\
\text { ngat Valid) }\end{array}$ & \\
\hline
\end{tabular}

Diagram 1: Hasil Akhir untuk Nilai Validasi modul tematik berbasis quantum learning dari Para Ahli (Ahli materi/konten, ahli desian/media dan ahli bahasa)

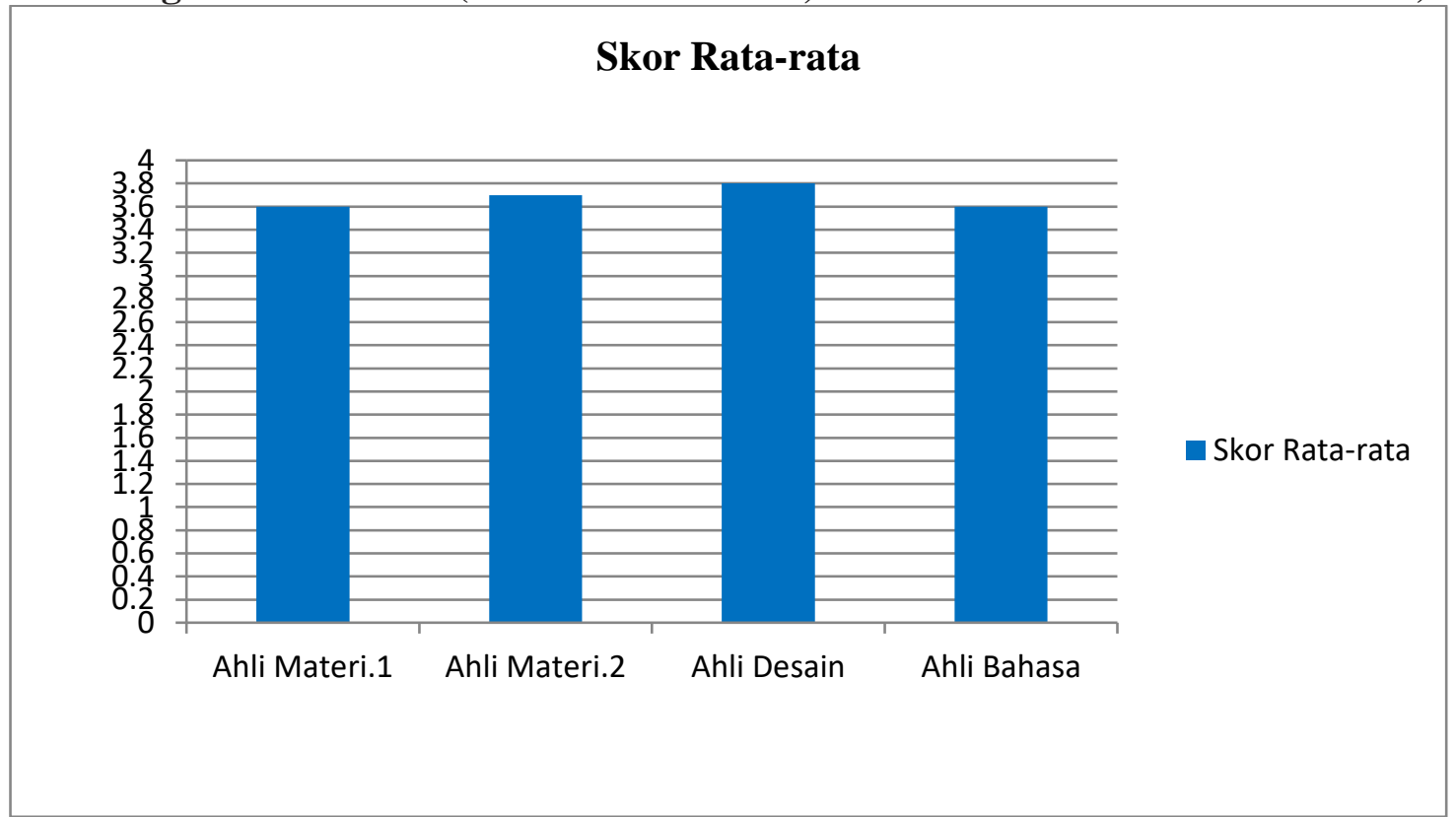

Pada diagram 1 hasil akhir untuk nilai validasi modul tematik berbasis quantum learning dari para ahli (ahli materi/konten,, ahhli desain/media dan ali bahasa memperoleh nilai rata-rata total 3.7 yang berada pada kategori sangat valid.

\section{PEMBAHASAN}

Pengembangan modul tematik terpadu berbasis Quantum Learning tema kayanya negeriku untuk siswa kelas IV SD 33 Kalumbuk telah berhasil dilaksanakan dengan baik. Paparan pembahasan mengenai hasil penelitian pengembangan yang telah dilakukan, akan diuraikan lebih lanjut terutama yang berkaitan dengan validasi, dan Modul yang dikembangkan. Adapun untuk lebih jelasnya dapat diuraiakan sebagai berikut:

\section{Pendefinisian (Define)}

a. Analisis Kurikulum, Depdiknas (2008: 8) yang menyatakan bahwa bahan ajar yang dikembangkan harus sesuai dengan kurikulum yang berlaku. Merujuk dari penjelasan diatas maka penulis hanya menambahkan model di dalam pengembangan modul yang penulis lakukan yaitu menggunakan modul tematik terpadu berbasis Quantum Learning.

b. Analisis Kebutuhan Peserta Didik, Prastowo menyatakan bahwa gambargambar yang mendukung dan memperjelas isi materi sangat dibutuhkan dalam pembuatan modul karena menambah daya tarik dan mengurangi kebosanan siswa dalam mempelajarinya (Prastowo, 2011). Dengan demikian, hal ini telah menjadi jawaban atas kendala penyajian materi pada bahan ajar tidak menarik.

Selain dari studi literatur, perlu juga dilakukan studi lapangan atau dengan kata lain disebut sebagai pengukuran kebutuhan dan penelitian dalam skala kecil (Sukmadinata: 2005). Dalam mengembangkan suatu produk, sebaiknya didasarkan atas 
pengukuran kebutuhan (need assessment). Maka dari itu didalam pengembangan modul berbasis Quantum Learning penulis membutuhkan yang namanya analisis kebutuhan baik untuk kurikulum maupun untuk peserta didik.

\section{Perancangan (Design)}

Berdasarkan dari hasil pendefinisian sebelumnya, dirancangkan Modul menggunakan model Quantum Learning pada pembelajaran tematik terpadu tema kayanya negeriku untuk siswa kelas IV SD, yang sesuai dengan kebutuhan kurikulum, dan kebutuhan peserta didik. Modul yang dirancang disesuaikan dengan Spesifikasi Penyususnan materi, alat dan bahan yang digunakan dan susunan perancangan modul yang kemudian disusun dengan langkah-langkah model Quantum Learning.

Berikut rancangan Modul tematik berbasis quantum learning :

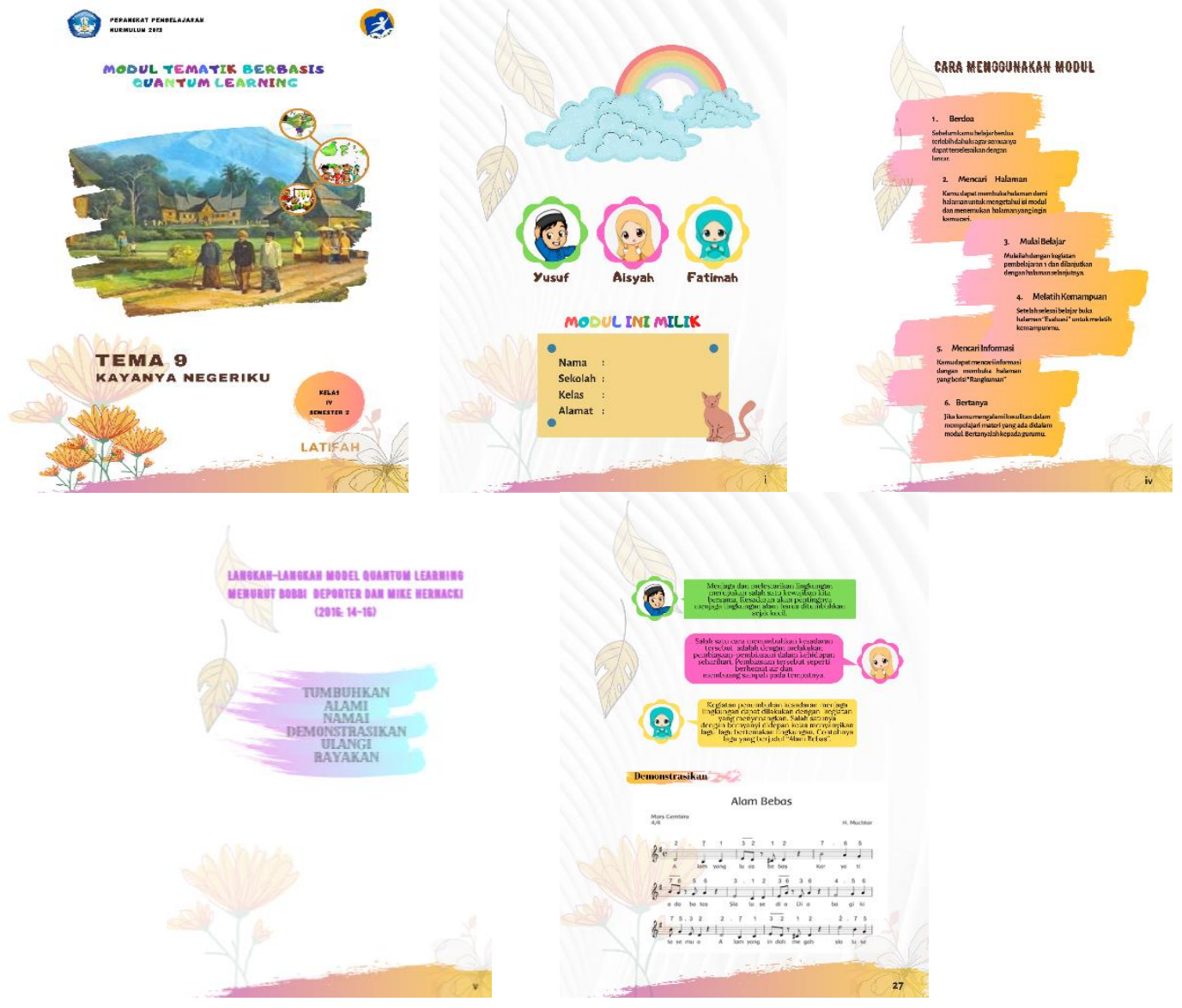

\section{Pengembangan (Develop)}

a. Tahap Validasi, Suatu modul hasil pengembangan dikatakan berkualitas apabila kriteria tersebut valid. Berdasarkan hasil penelitian diketahui bahwa sumber belajar model Quantum Learning sudah valid bahkan bisa dikatakan sangat valid. Aspek yang dinilai untuk validitas modul adalah aspek materi/konten, desain/media dan bahasa. Validasi modul dilakukan oleh 4 orang pakar, 2 orang pakar tematik yakni Silfi Melindawati,M.Pd dan J Jiyanto, S.Pd, 1 orang pakar teknologi pendidikan (ahli desain/media) yakni Alfiyandri, dan 1 orang pakar kebahasaan (ahli bahasa) yakni Dr. Jendriadi, M.Pd.

Setelah melakukan validasi diperoleh hasil validasi modul dalam aspek materi/konten adalah 3.7 yang tergolong sangat valid. Dari aspek penyajian dapat disimpulkan bahwa modul sudah memuat petunjuk penggunaan modul, melibatkan peserta didik secara aktif, serta memotivasi peserta didik untuk mempelajari modul secara mandiri sesuai dengan pengertiannya Modul merupakan bahan ajar yang disusun secara sistematis dengan bahasa yang mudah dipahami oleh siswa, sesuai usia dan 
tingkat pengetahuan mereka agar mereka dapat belajar secara mandiri dengan bimbingan minimal dari pendidik (Prastowo, 2012: 106).

Aspek yang dinilai selanjutnya adalah aspek desain/media. Berdasarkan validasi aspek desain/media, diperoleh nilai 3,7 yang tergolonng sangat valid. Hal ini menunjukkan bahwa aspek pada bagian desain/media sudah memenuhi aspek yang diharapkan seperti pemilihan huruf, warna, gambar, ukuran yang tepat sebagai pendukung terlaksananya pembelajaran berbasis model Quantum Learning. Dan aspek yang terakhir dinilai yakni aspek bahasa. Berdasarkan validasi aspek bahasa, diperoleh nilai 3,6 yang tergolong sangat valid. Hal ini menunjukkan bahwa petunjuk penggunaan modul jelas, bahasa yang digunakan sudah sesuai dengan Pedoman Umum Ejaan Bahasa, informasi yang disampaikan jelas, kalimat sudah komunikatif serta bahasa yang digunakan sudah sesuai dengan tingkat pemahaman peserta didik.

Modul yang dikembangkan telah valid karena dalam proses pengembangannya telah didasarkan pada teori-teori yang relevan. Namun demikian, meskipun telah dinyatakan sangat valid, masih ada beberapa butir yang berada dalam kategori valid yaitu pada masing-masing aspek penyajian materi/konten, desain, dan bahasa.

b. Tahap Revisi, Hasil penilaian produk Modul dari validator ahli, disampaikan bahwa Modul tematik terpadu berbasis Quantum Learning tema kayanya negeriku untuk siswa kelas IV SD secara keseluruhan sudah baik, namun ada beberapa masukan dan saran demi menyempurnakan desain Modul tersebut sebelum digunakan. Berikut perbaikan yang disarankan adalah sebagai berikut:

1) Untuk kata SWT dikata pengantar modul diganti menjadi Swt.

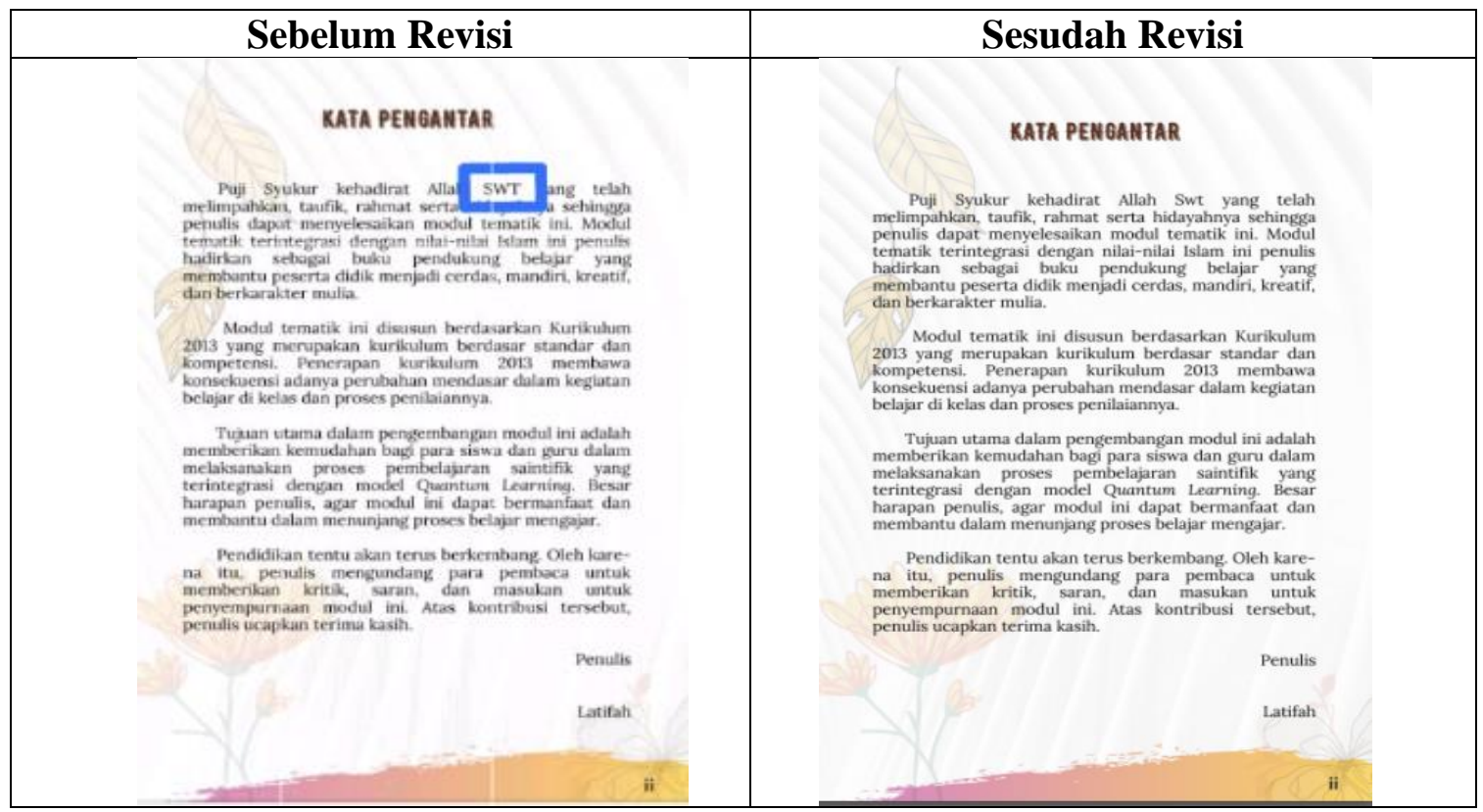


2) Untuk pemetaan kompetensi dasar pada modul hal vi ganti warna.

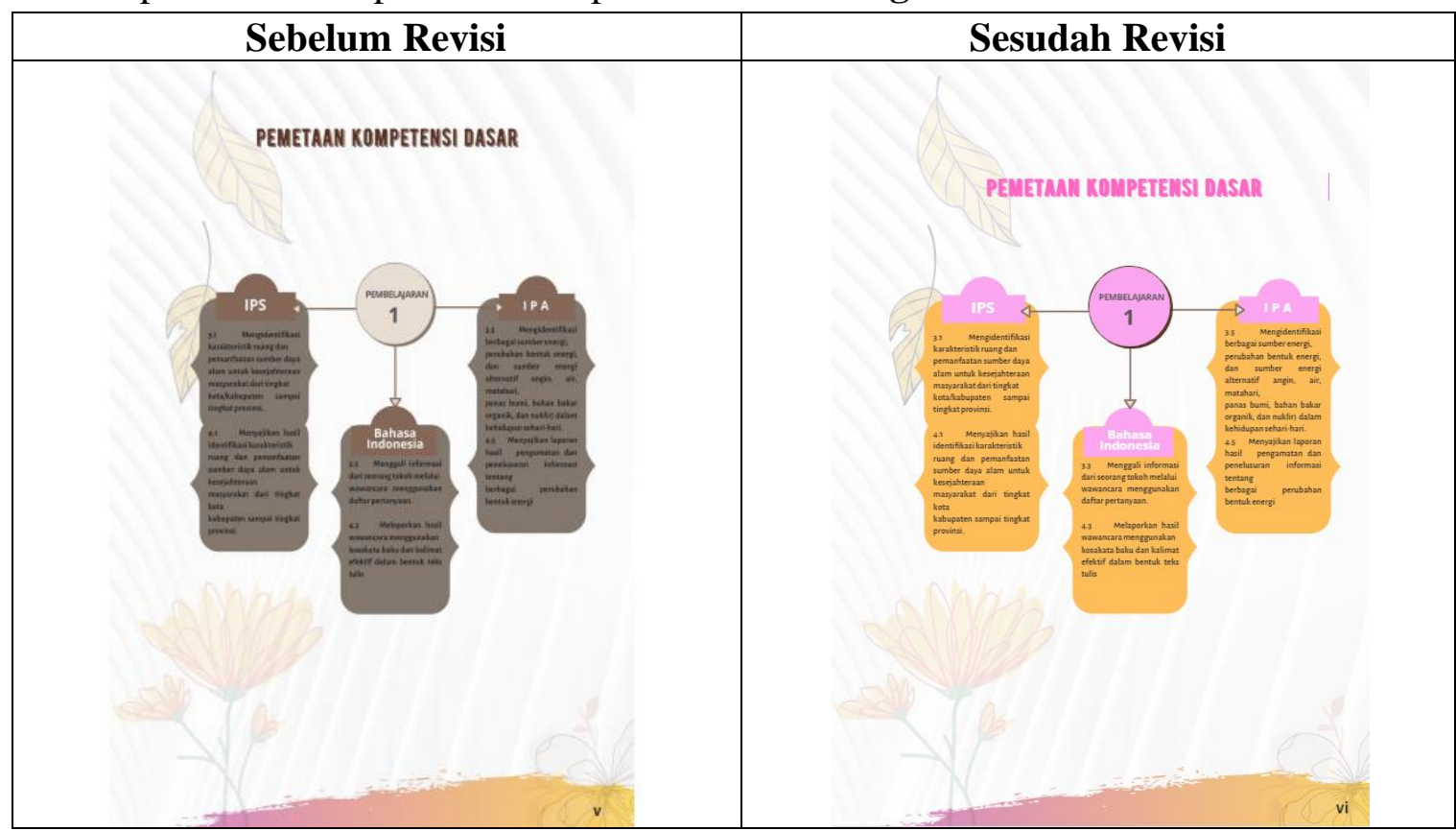

3) Tokoh Aisyag bertukar dengan Fatimah, dan untuk tulisan didalam kolom diperjelas pada buku modul halaman 21

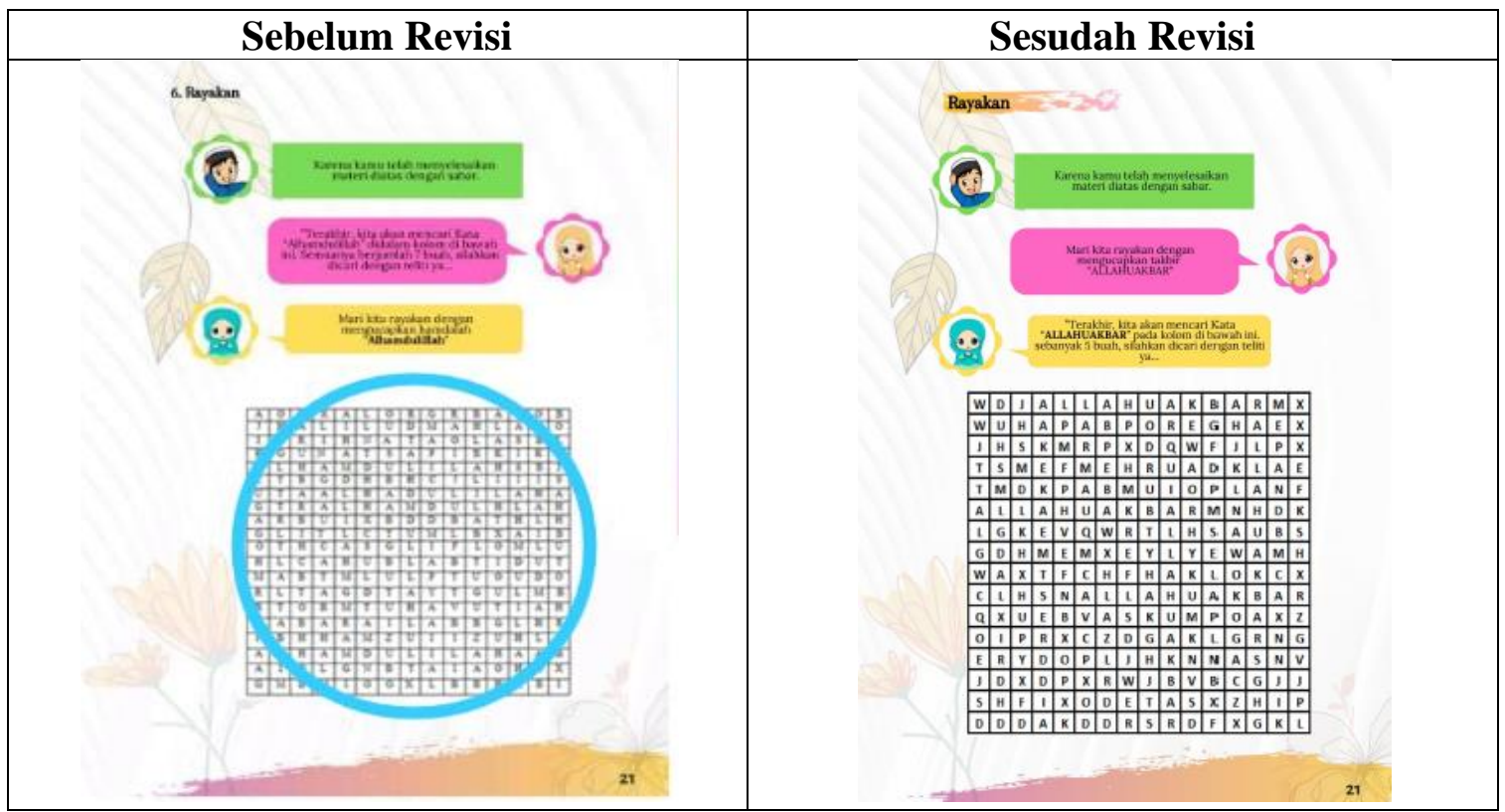


4) Untuk daftar rujukan pada buku modul cantumkan sumber dan kapan dikutip, pada buku modul halaman 37

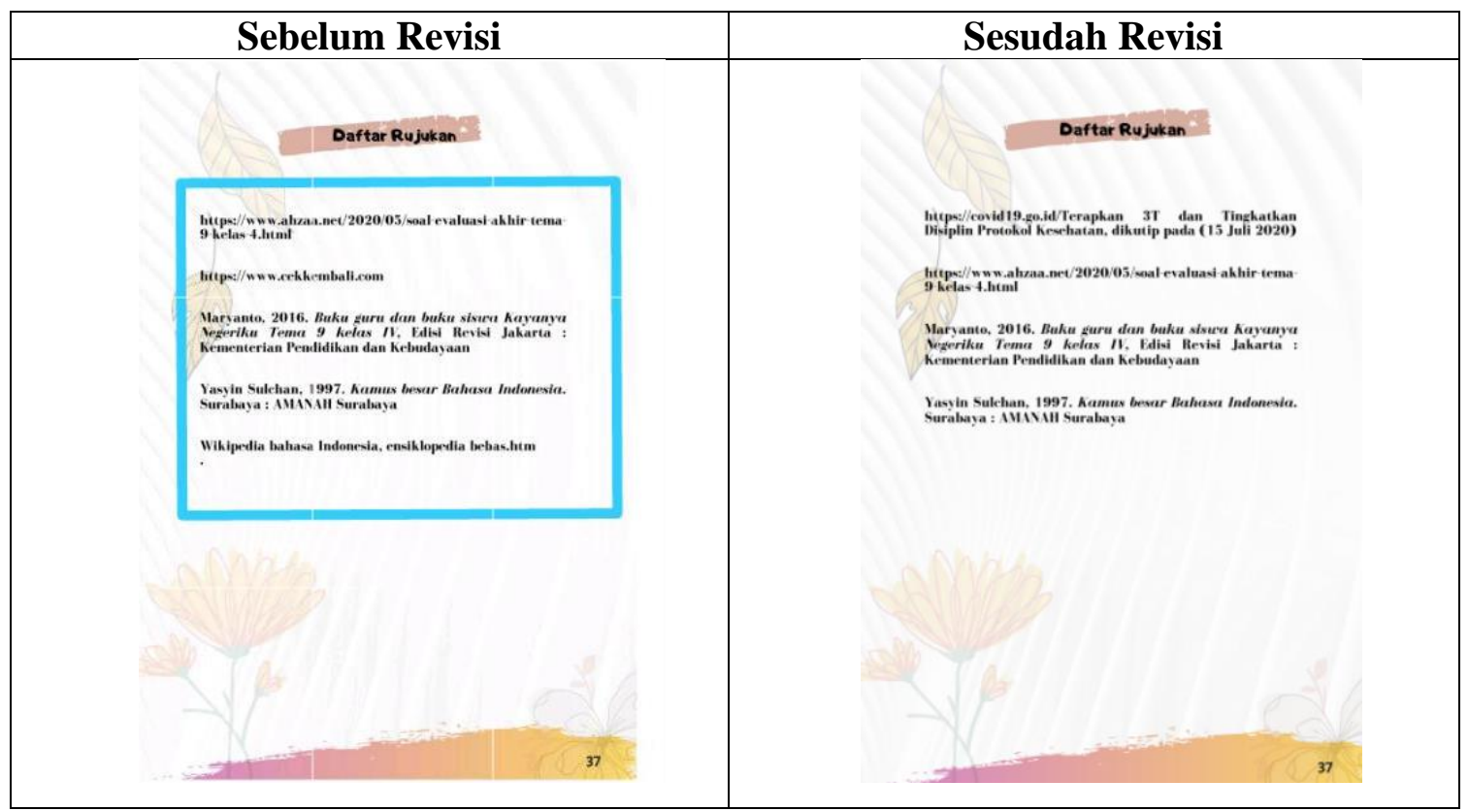

5) Untuk kata ADZKIA dibagian riwayat penulis dalam buku modul diiganti menjadi Adzkia, di halaman 38 .

\begin{tabular}{|c|c|}
\hline Sebelum Revisi & Sesudah Revisi \\
\hline REWAYAT PENULIS & NAYAT PENULIS \\
\hline Latran & Latifath \\
\hline 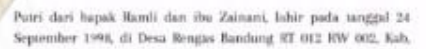 & 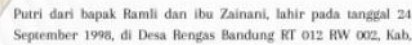 \\
\hline 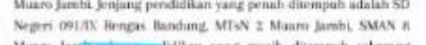 & 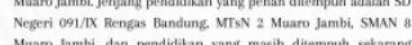 \\
\hline 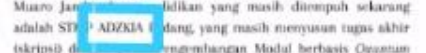 & 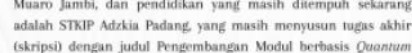 \\
\hline 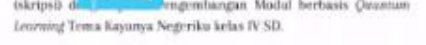 & 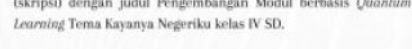 \\
\hline 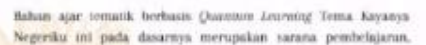 & 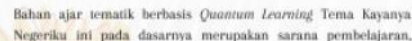 \\
\hline pert & 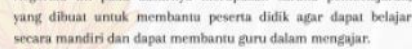 \\
\hline 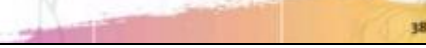 & \\
\hline
\end{tabular}




\section{PENUTUP}

Berdasarkan hasil penelitian yang telah dirumuskan, maka diambil kesimpulan sebagai berikut :

1. Proses pengembangan modul berbasis Quantum Learning tema kayanya negeriku kelas IV SD dilakukan dengan tahap pendefinisian, perancangan, pengembangan dan penyebaran. Dapat dijelaskan sebagai berikut : 1) tahap pendefinisian adalah melakukan analisis buku guru dan buku siswa, 2) tahap perancangan dilakukan dengan merancang bentuk produk modul siswa dan buku guru dengan menggunakan model Quantum Learning, 3) tahap pengembangan dilakukan dengan uji validitas modul oleh validator yang berkompeten dibidangnya, dan 4) tahap penyebaran tidak dilakukan karena menimbang kondisi pandemi (COVID19) yang tidak memungkinkan untuk terjun kelapangan.

2. Dihasilkan modul tematik terpadu berbasis Quantum Learning tema kayanya negeriku kelas IV SD yang valid. Hal ini dapat dilihat dari hasil validasi modul oleh validator ahli materi dan ahli desain, yang telah dilaksanakan. Modul yang dikembangkan mendapatkan skor rata-rata yaitu 3,7 dengan kategori Sangat Valid. Hal ini memberikan gambaran bahwa modul yang dikembangkan telah valid dan dapat digunakan dalam pembelajaran tematik terpadu.

\section{DAFTAR PUSTAKA}

Ambarita, A., Intan, P., Janah, N. U. R., \& Tarigan, H. (2020). Pengaruh model quantum teaching terhadap kemampuan berpikir kritis peserta didik pada pembelajaran matematika kelas v sdn. Aquinas Jurnal Ilmiah, 3(2), 187-207. Retrieved from http://ejournal.ust.ac.id/index.php/Aquinas/article/view/712

Chan, F., Kurniawan, A. R., Herawati, N., Nur, R., \& Mulyani, J. S. (2019). Strategi Guru Dalam Mengelola Kelas di Sekolah Dasar. International Journal of Elementary Education, 3(4), 439-446.

DePorter, B., Reardon, M., \& Singer-Nouri, S. (2010). Quantum Teaching. Bandung: Penerbit Kaifa.

Izzati, N., Hindarto, N., \& Pamelasari, S. . (2013). Jurnal Pendidikan IPA Indonesia. Jurnal Pendidikan IPA Indonesia, 2(2), 183-188. Retrieved from https://journal.unnes.ac.id/nju/index.php/jpii/article/view/2721/2785

Prastowo, A. (2011). Pengembangan Sumber Belajar. Yogyakarta: Fak. Tarbiyah Sunan Kali Jaga.

Purwanto, R., \& Lasmono, S. (2007). Pengembangan Modul. Jakarta: PUSTEKKOM Diknas.

Sugiyono. (2010). Metode penelitian pendidikan (Pendekatan Kuantitatif, Kualitatif, $R$ dan D). Bandung: Alfabeta.

Thiagarajan, S. (1974). Thiagarajan, Sivasailam; And Others Instructional Development for Training Teachers of Exceptional Children: A Sourcebook. Indiana Univ., Bloomington. Center for Innovation in. Washington DC: National centerfor Improvement of Educational SYstem. Retrieved from https://files.eric.ed.gov/fulltext/ED090725.pdf 